\title{
Measurements of Dissolved Oxygen Concentration in Stationary Water
}

\author{
Ale xandru Pătulea, Nicolae Băran*, Ionela Mihae la Căluş aru \\ Faculy of Mechanical and Mechatronics Engineering, Politehnica University of Bucharest, Bucharest, 060042, Romania
}

\begin{abstract}
The paper justifies the need for measuring the concentration of oxygen dissolved in stationary waters; in order to perform accurate measurements, the oxygen probe must be displaced inside water with a speed greater than 0,3 $\mathrm{m} / \mathrm{s}$. The performed experimental researches proved the accuracy of probe displacement and the reliability of the driving mechanism. The constructive solution of the driving mechanis $\mathrm{m}$, its functioning and the results of the performed measurements are exposed.
\end{abstract}

Keywords Water Oxygenation, Stepping Motor, Microcontroller

\section{Introduction}

An important indicator of the water quality is the quantity of dissolved oxygen[1,2]; among water molecules there are oxygen molecules that constitute the dissolved oxygen.

Oxygen dissolved in water is known as dissolved oxygen DO (fig.1) and is conventionally measured in $\mathrm{mg} \mathrm{O}_{2} / \mathrm{l}$.

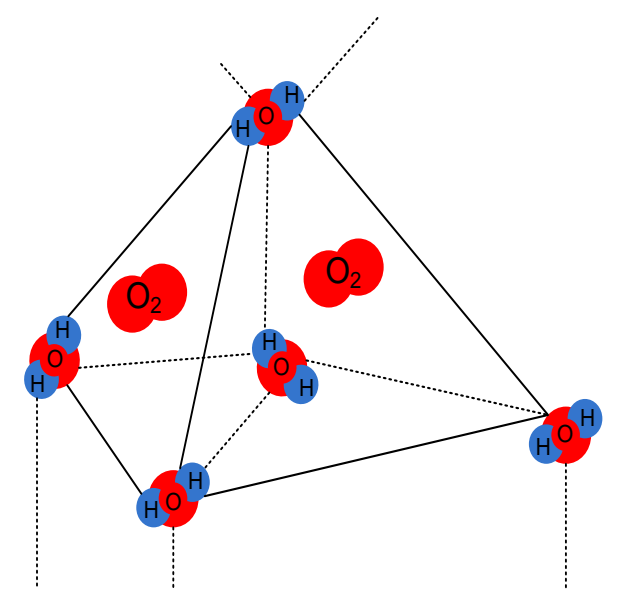

Figure 1. View of molecular structure: dissolved oxygen

Oxygen molecules that constitute the dissolved oxygen DO can be found among water molecules[2,3].

The maximum quantity of oxygen that can be dissolved (absorbed in water) depends on a number of physical and chemical parameters[4] atmospheric pressure or pressure exerted on water:

1) water temperature;

* Corresponding author:

n_baran_fimm@yahoo.com (Nicolae Băran)

Published online at http://journal.sapub.org/env

Copyright (C) 2012 Scientific \& Academic Publishing. All Rights Reserved
2) water salinity (amount of salts in water);

3) water clearness.

The aeration is used[5]: in water treatment processes, in order to eliminate dissolved inorganic substances or chemical elements as iron, manganese etc. by oxidation and formation of sedimentable compounds or compounds that can be retained through boiling; for the biologic purification of wastewaters by the active mud process or in biofilters; in the disinfection by ozonization of crude water captured from a source in order to convert it into potable water; during separation and collecting emulsified greases from used waters.

DO concentration in water can be measured by a number of methods [6]:

a) chemical methods;

b) electrical methods;

c) optical methods.

A high content of DO must be preserved in the fish farms; if the DO level decreases below $2 \mathrm{mg} / \mathrm{l}$, the fishes start to suffocate. Therefore the need of measuring the content of DO in basins or tanks appears. The measurement of DO concentration is performed using chemical, electric or optical methods.

A process of DO measurement using an oxygen meter endowed with a polarographic probe, belonging to the class of electrical methods, will be presented in continuation.

The oxygen meter manufactured by Hanna Instruments, Canada [7], requires a water speed of minimum $0,3 \mathrm{~m} / \mathrm{s}$ in order to perform accurate measurements.

During our research, the basin water will be stationary and the probe driven by a stepping motor will be displaced in the water with a speed of $0,39 \mathrm{~m} / \mathrm{s}$.

\section{Description of the DO Measuring Instrument}


The oxygen dissolved in water is measured in parts per million (ppm=mg/l) or in saturation percentages (\%).

The electric method, also known as electro-chemical method, is based on two ways of measuring DO concentration:

a) Galvanic procedure, where a small electric voltage appears between the electrodes; applying an external voltage is not needed;

b) Polarographic procedure, where a DC voltage is applied between the two electrodes (cathode and anode).

A HI 9146 oxygen meter manufactured by HANNA INSTRUMENTS (Canada) was purchased for experimental researches. The oxygen meter uses the polarographic procedure as measurement technique. The oxygen meter is composed of a microprocessor (1) (fig.2) that, through the connection cable (2), establishes the connection with the measurement probe (3) introduced in the water whose DO content must be established [7].

Figures 2, 3 and 4 present the component elements of the oxygen meter as well as their assembling manner in order to perform DO measurements. A small cylinder (4) (fig.4) that contains an electrolyte solution is screwed on the threaded portion (5) (fig.3). The cylinder base consists of an oxygen permeable Teflon membrane (5). The functioning principle of the measuring instrument is the following: a d.c. battery is mounted inside the microprocessor(1), thus an electric field where ions migrate is established between the probe electrodes. A special purpose electrolyte solution, contained in a small cylinder tube (4) isolated to water, lies between the electrodes.

The intensity of the electric current between the anode and the cathode varies in function of the concentration of dissolved $\mathrm{O}_{2}$, therefore the value of the $\mathrm{O}_{2}$ concentration displayed by the oxygen meter also changes.

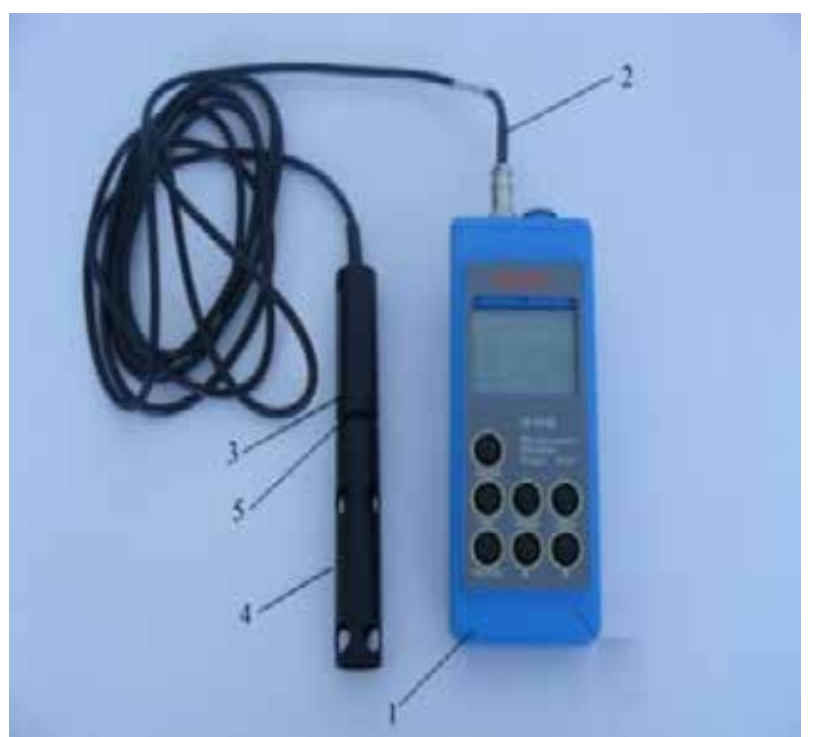

1- microprocessor with digital display; 2 - connection cable; 3 - probe body; 4 - protection cylinderthat can be unscrewed during measurements; 5 - threaded portion of the probe body wherethe part 4 is screwed.

Figure 2. General view of the oxygen meter

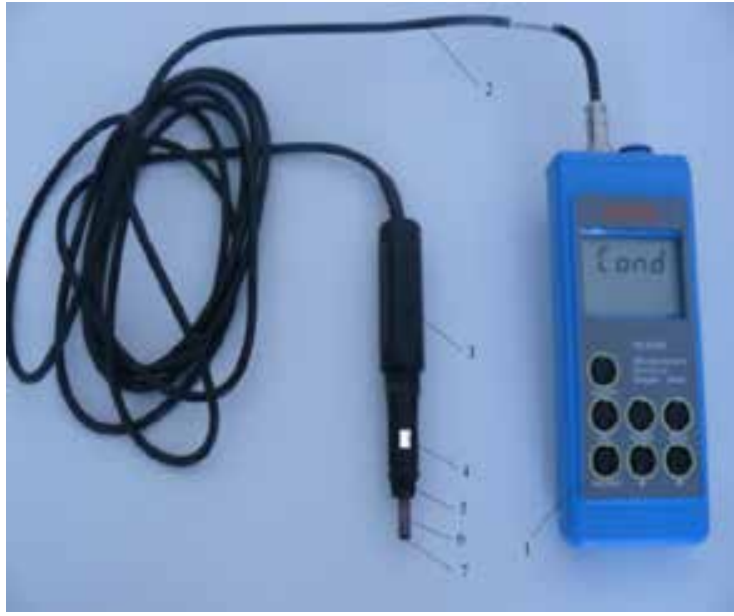

1- microprocessor with digital display; 2 - connection cable; 3 probe body; 4 -temperature sensor; 5 - threaded portion of the probe body where the part 4 (fig.2) is screwed; 6 - anode; 7 - cathode.

Figure 3. General view of the oxygen meter without protection cap

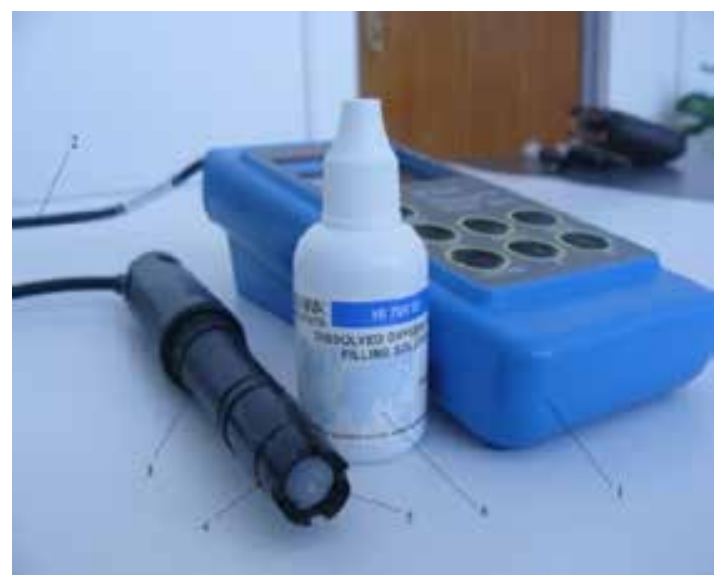

1- microprocessor; 2 - connection cable; 3 - probe body; 4 - small cylinder that contains an electrolyte solution; 5 - oxygen permeable Teflon membrane; 6 - solution vail.

Figure 4. Assembly view of the oxygen meter prepared for measurements

\section{The Experimental Stand for the Measurement of the Oxygen Dissolved in Water}

The experimental stand (fig.5) consists of the following elements:

- an air electro-compressor (1);

The compressor is endowed with a pressure reducer (2) that assure the required work pressure and a mano meter (3).

- a joint for exhausting of air in the atmosphere (4);

- a compressor feeder (5);

- a rotameter (6) for air flow rate measuring;

- a digital thermo meter for measuring the air temperature found on the measuring instruments panel (8);

- a dig ital manometer for measuring the air pressure at the entrance of the fine air bubble generator (FBG) found on the measuring instruments panel (8);

- a pipe (9) for the transport of the compressed air towards 
the FBG;

- a tank (10) filled with water from the plant supply, where the FBG is immersed;

- a driving mechanism (11) of the measurement probe (12).

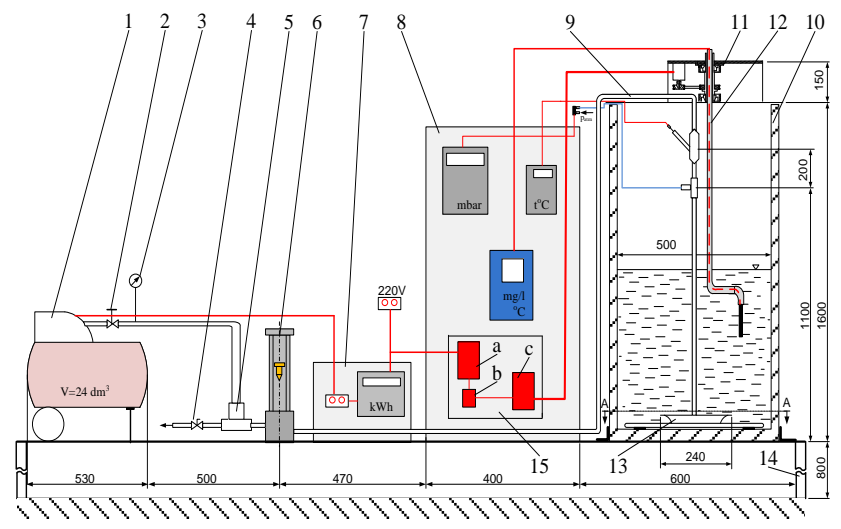

1- electro compressor with air tank; 2 - pressure reducer; 3-manometer; 4-joint for exhausting of air in the atmosphere; 5- compressor feeder; 6- rotameter; 7- electric panel; 8-measuring instruments panel; 9- pipe for the transport of the compressed air towards the FBG; 10- water tank; 11- mechanism for probe driving; 12- oxygen meter probe; 13- FBG; 14- holder for the plant; 15-control electronics (a - supply unit, b- switch, c- control element).

Figure 5. Sketch of the experimental setup for researches regarding water oxygenation

An energy meter was used in order to measure the electric energy consumption found on the electric panel (7).

The air discharged by the compress or covers the following path:

- through the rotameter (6), where its pressure is measured;

- its temperature and pressure are subsequently measured;

- finally enters the FBG (13) that emits air bubbles;

- the increase of $\mathrm{O}_{2}$ concentration is measured using the oxygen meter found on the measuring instruments panel (8).

Measures will be taken that the air pressure in the tank (10) remains constant during the measurements.

The pressure reducer (2) allows keeping a constant pressure at the entrance of the air in FBG.

\section{Device for the Displacement of the Polarografic Probe}

The instruction manual of the oxygen meter specifies that, in order to obtain accurate measurements, water must flow with a flow speed of minimum $0,3[\mathrm{~m} / \mathrm{s}]$.

In our case, the water is stationary in the water tank, thus we will displace the probe on a circular path in the horizontal plane.

A circle with a diameter of $\mathrm{D}=0,25 \mathrm{~m}$ is chosen.

Accordingly, the length of the path is equal to:

$$
L=\pi D=\pi 0,25=0,785[\mathrm{~m}]
$$

If the circle is travelled in two seconds, it results a probe speed equal to:

$$
v_{s}=\frac{L}{\tau}=\frac{0,785}{2}=0,3925[\mathrm{~m} / \mathrm{s}]
$$

thus upper than the minimum speed of $0,3[\mathrm{~m} / \mathrm{s}]$.

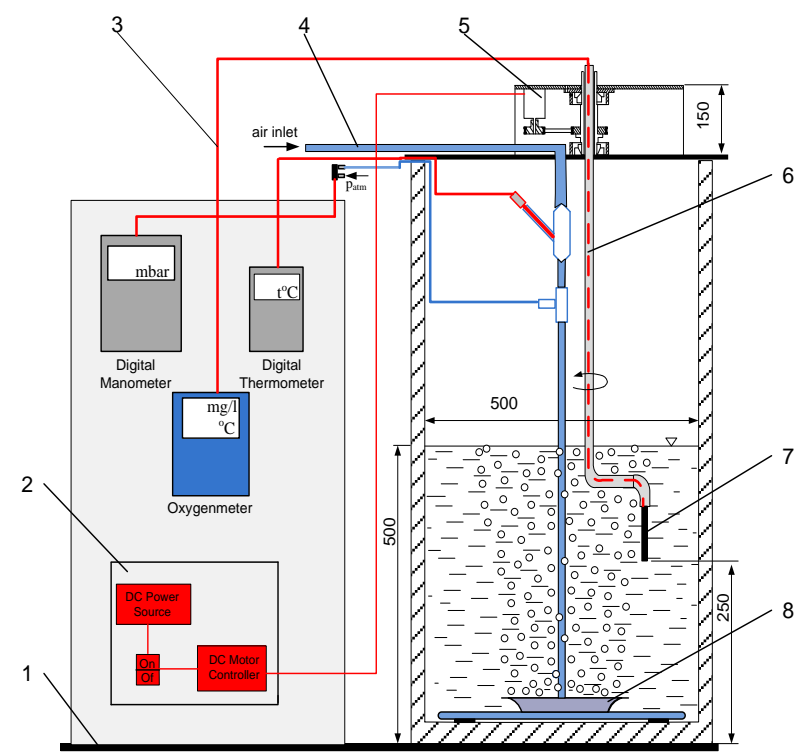

1-base plate; 2- electronic control pan el; 3- connection cable between the probe and the oxygen meter separation plate; 4- compressed air supply pipe ; 5 - carrier rod of the probe; transparent plexiglass tank; 6- device for rod driving; 7- oxygen meter probe; 8- fine bubble generator.

Figure 6. Sketch of the water tank and of themeasurement probe

The displacement device of the oxygen meter probe is mounted on the upper part of the water tank (fig. 5).

The electric motor drives the rod carrying the probe in a rotation movement on a circle $\varnothing 250$ with a speed of 0,39 $\mathrm{m} / \mathrm{s}$.

A detailed representation of the driving mechanis m of the oxygen meter probe is presented in figure 7 .

The mechanis m consists of: stepping motor (4) that drives the gear wheel (2) joint to the central bushing (8) through a gear wheel (6) and a gear belt (5).

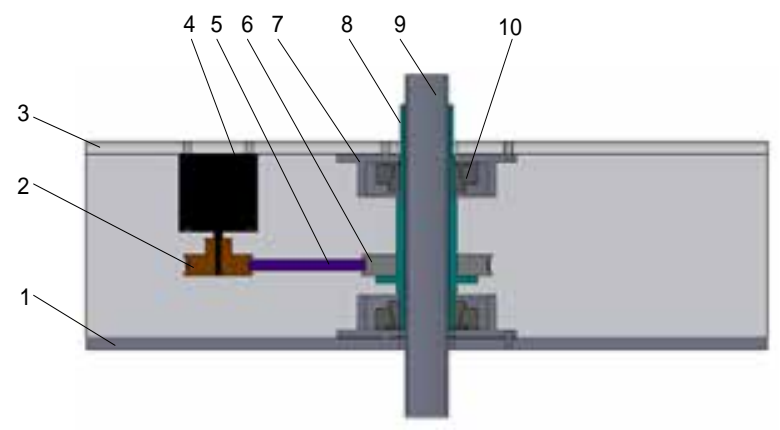

1- base plate; 2- gear wheel coupled on the motor shaft; 3- upper plate; 4- stepping motor; 5-gear belt; 6- gear wheel; 7- conical bearing case; 8-central bushing; 9-carrier rod of the probe; 10 - conical bearings.

Figure 7. Device for driving the oxygen meter probe in a circular movement

The central bushing is mounted on a pair of conical bearings (10) and allows the fixing of the carrier rod (9).

The movement is therefore transmitted from the motor to the carrier rod, assuring the rotating movement of the oxygen 
probe.

Figure 8 presents an image of the driving mechanis $m$.

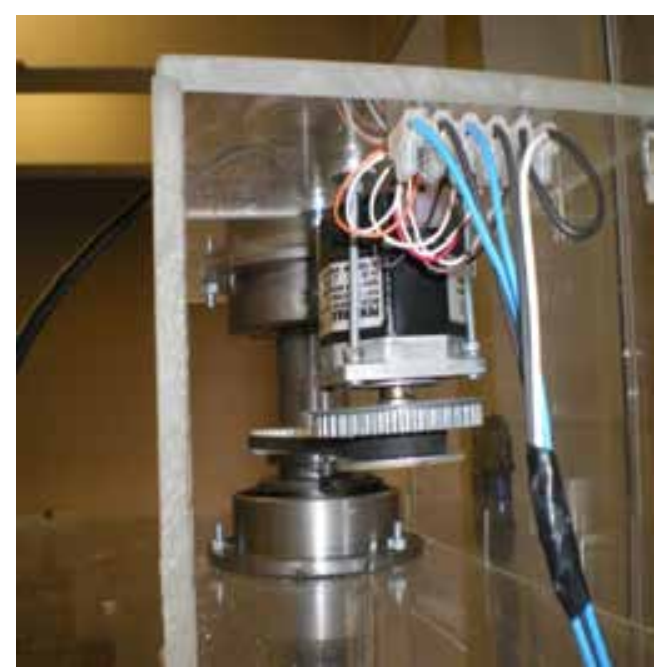

Figure 8. Driving mechanism

A POWERMAX II type P21NSXS-LSS-NS-03 stepping motor, manufactured by ScientificPacific, was chosen.

The motor features a step of $1,8^{\circ}$ and a maximum torque of $1,2 \mathrm{Nm}$.

The control electronics of the positioning system of the oxygen probe must guarantee the correct step sequence of the stepping motor in order to achieve the rotating movement of the probe.

The electronic system can be controlled through a number of knobs that allow the accomplishment of a preestablished rotation sequence in both directions, with a speed of 0,5 rps, or the positioning of the probe by the operator in the desired position [8].

The electronic system is based on a PIC16F628A microcontroller that can be programmed to perform measurement cycles more complex that the considered one.

The work program contains an initialization sequence when it waits $5 \mathrm{~s}$ without any visible action, then a short cycle of 20 steps left-right.

Afterwards the system can receive instructions from the operator.

If the operator chooses the automatic mode of functioning, the microcontroller will perform a sequence of 400 steps, equivalent to a complete rotation of the carrier rod (established from the trans mission ratio and the number of steps corresponding to a rotation of the motor).

In the manual mode, the microcontroller will perform continuous sequences of steps as long as the control knobs is pressed.

The probe can thus be positioned in the measurement points.

\section{Computation of the Performance and of the Efficiency of the Oxygenation Process}

It is known from specialty literature $[9,10]$ that the performance of the water oxygenation is defined as ratio between the oxygen dissolved in water and the oxygen introduced in water:

$$
\eta_{o x}=\frac{V}{n \log _{2}} \frac{d C}{d \tau}=\frac{V}{\rho_{O_{2}} \frac{V}{O_{2}}} \cdot a K_{L}\left(C_{s}-C\right)
$$

Where:

$V$ - volu me of the water subjected to oxygenation $\left[\mathrm{m}^{3}\right]$; $m_{\mathrm{O}^{2}}$ - flow rate of the oxygen introduced in water $[\mathrm{kg} / \mathrm{s}]$; $d C / d \tau$ - transfer speed of the dissolved oxygen $\left[\mathrm{kg} / \mathrm{m}^{3} \cdot \mathrm{s}^{-1}\right]$ $a K_{L}-$ mass transfer volu metric factor $[\mathrm{l} / \mathrm{s}]$;

$C_{s}$ - mass concentration of the component transferable at saturation in the liquid phase $\left[\mathrm{kg} / \mathrm{m}^{3}\right]$;

$C$ - current mass concentration of the component transferable in the liquid phase $\left[\mathrm{kg} / \mathrm{m}^{3}\right]$.

The oxygenation performance can be established in two situations:

In stationary conditions, the amount of oxygen introduced in the tank is consumed by the fishes and other creatures living in water; in this case $d C / d \tau=c t$, the transfer speed of the dissolved oxygen is constant.

Mathematically, the variation of the concentration of dissolved $\mathrm{O}_{2}$ in function of time.

$$
\left(\frac{d C}{d \tau}\right)_{B}=\frac{\Delta C}{\Delta \tau}=c t
$$

This value stays constant in the case of stationary conditions. Thus in the case of stationary conditions the oxygenation performance is constant.

In the case of non-stationary conditions a quantity of air (thus $\mathrm{O}_{2}, 21 \%$ ) is introduced.

The concentration of $\mathrm{O}_{2}$ dissolved in water varies in time, namely increases.

Consequently the slopes of the graph $C_{O^{2}}=f(\tau)$ will be different.

The slope between two successive points:

$$
\frac{\Delta C}{\Delta \tau}=\frac{C_{i+1}-C_{i}}{\tau_{i+1}-\tau_{i}}
$$

This value, experimentally established, helps us to compute:

$$
\frac{\Delta C}{\Delta \tau}=a K_{L}\left(C_{s}-C\right)
$$

where $a K_{L}$ is difficult to establish.

The value $d C / d \tau$ is successively computed only for the first stage:

$\left(\frac{d C}{d \tau}\right)_{A B}=\frac{C_{2}-C_{1}}{\tau_{2}-\tau_{1}}=\frac{(8,30-7,72)[\mathrm{mg} / \mathrm{ll}]}{15 \cdot 60[\mathrm{~s}]}=0,0644 \cdot 10^{-5}\left[\frac{\mathrm{kg}}{\mathrm{m}^{3}} \cdot \frac{1}{\mathrm{~s}}\right]$ (7)

During the non-stationary conditions, the oxygenation performance for the first functioning stage will be:

$$
\eta_{o x}=\frac{V}{h \delta_{\sigma_{2}}} \cdot \frac{d C}{d \tau} \cdot 100[\%]
$$

$V$ - volu me of water $\mathrm{V}=0,125 \mathrm{~m}^{3}$;

$m_{\mathrm{O}_{2}}$ - flow rate of the oxygen introduced in water $[\mathrm{kg} / \mathrm{s}]$;

It is known from specialty literature [9] that:

$$
n \delta_{2}=0.233 n \delta_{a e r}[\mathrm{~kg} / \mathrm{s}]
$$




$$
\dot{m}_{\text {aer }}=\rho_{\text {aer }} \cdot \dot{\boldsymbol{V}}_{\text {aer }}
$$

Air density is computed from the thermal equation of states[11]:

$$
\rho_{\text {aer }}=\frac{p_{a e r}}{R T_{\text {aer }}}\left[\mathrm{kg} / \mathrm{m}^{3}\right]
$$

The performance and the efficiency of water oxygenation, established during experimental research $(\eta=0,16 \%)$ have reduced values because:

The initial concentration of the oxygen dissolved in water is high $C_{0}=7,72 \mathrm{mg} / \mathrm{l}$ and $C_{s}=8,9 \mathrm{mg} / \mathrm{l}$;

The water column above FBG has a small height $(h=0.5$ $m$ ), the time of contact between the air bubble and water is reduced.

\section{Measurement Results}

In the experimental stand, a column of water of height $H=500 \mathrm{~mm} \mathrm{H}_{2} \mathrm{O}$ lies above the perforated plate.

The pressure generated by the surface tension $[9,11]$ is equal to:

$$
\begin{gathered}
p_{t s}=\frac{2 \sigma}{r_{0}}=\frac{2 \cdot 8 \cdot 10^{-2}}{0,25 \cdot 10^{-3}}=620 \mathrm{~N} / \mathrm{m}^{2} \\
\Delta h_{t s}=\frac{p_{t s}}{\rho_{H 2 O} \cdot g}=\frac{620}{10^{3} \cdot 9,81}=0,063 \mathrm{mH}_{2} \mathrm{O}
\end{gathered}
$$

Hereupon the first gas bubbles will appear if the digital mano meter will display:

$$
\Delta h_{1}>H+\Delta h_{t s} \Rightarrow \Delta h_{1}>563 \mathrm{mmH}_{2} \mathrm{O}
$$

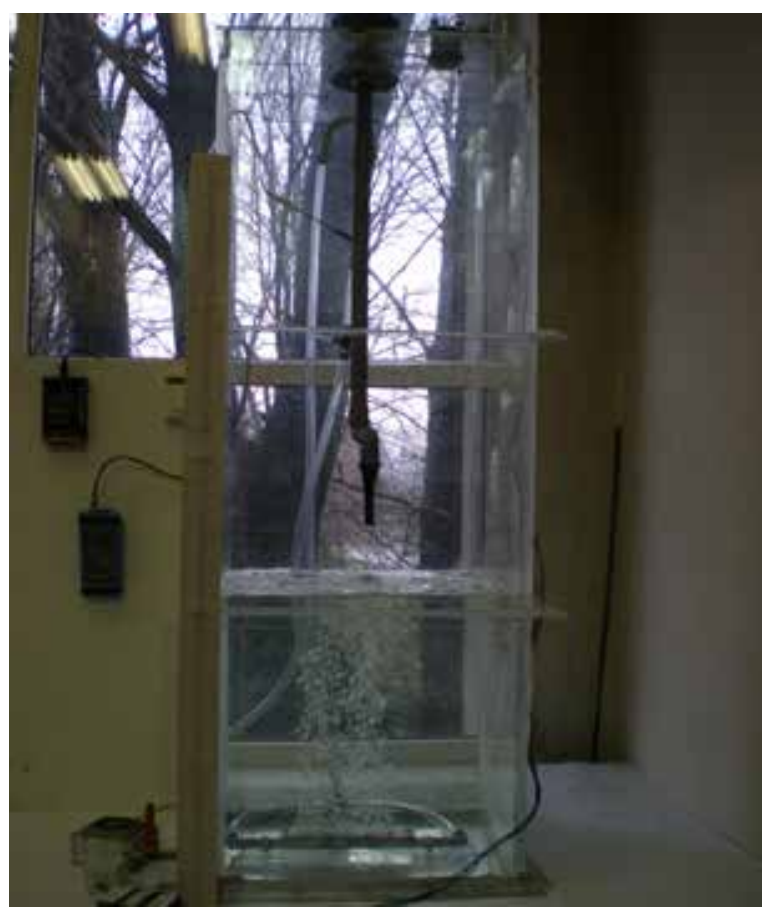

Figure 9. FBG in function

Previous researches[12-14] proved that the air pressure at the entrance to $\mathrm{FBG}$ had to be equal to $611 \mathrm{mmH}_{2} \mathrm{O}>563$ $\mathrm{mmH}_{2} \mathrm{O}$, therefore the FBG functioned normally.
The measurements were performed in eight stages.

At the beginning of the first stage, where the height of the water layer over the $\mathrm{FBG}$ is $\mathrm{h}_{\mathrm{H} 2 \mathrm{O}}=500 \mathrm{~mm}$, the probe is situated at $\mathrm{h}_{\text {probe }}=250 \mathrm{~mm}$ with respect to the nozzle plate, the initial $\mathrm{O}_{2}$ concentration being $\mathrm{C}_{0}=7,72 \mathrm{mg} / \mathrm{l}$, the indication of the electric counter $\mathrm{E}_{0}=0,0325 \mathrm{kWh}$ and water temperature $t=20,5^{\circ} \mathrm{C}$. Pressure and flow rate of air that enters the FBG are measured: $\mathrm{p}_{1}=583,44 \mathrm{mmH}_{2} \mathrm{O} ; \mathrm{V}_{1}=600$ l/h.

These values are kept constant during measurements. After a functioning of the FBG for $\Delta \tau_{1}=15^{\prime}$, it is stopped and $\mathrm{O}_{2}$ concentration is measured by rotating the probe in water.

The FBG is put in functioning again and air is blasted in water during $15^{\prime}$, the total time being $\Delta \tau_{2}=30^{\prime} ; \mathrm{O}_{2}$ concentration is measured.

Similarly, the time values of $\Delta \tau_{3}=45^{\prime}, \Delta \tau_{4}=60^{\prime}, \Delta \tau_{5}=75^{\prime}$, $\Delta \tau_{6}=90^{\prime}, \Delta \tau_{7}=105^{\prime}, \Delta \tau_{8}=120^{\prime}$ are reached.

Finally, the concentration of $\mathrm{O}_{2}$ dissolved in water after two hours of FBG functioning is measured.

The measured values are presented in table 1.

Table 1. Variation of $\mathrm{O}_{2}$ concentration in function of the functioning time of the FBG

$\left.\begin{array}{|c|c|c|c|}\hline \multicolumn{4}{|c|}{\text { Values of the concentration of } \mathrm{O}_{2} \text { dissolved in water }} \\ {[\mathrm{mg} / \mathrm{l}]}\end{array}\right]$

The chart $\mathrm{C}_{\mathrm{O} 2}=\mathrm{f}(\tau)$ from figure 10 , is traced based on data presented in table 1 .

The oxygen transferred to the clean water(from the plant supply) was not consumed either as consequence of the microorganis $m$ metabolis $\mathrm{m}[15,16]$ (see reactors, water treatment plants) or by the fishes, thus the concentration of oxygen in water increased in proportion as air was blown in the water tank.

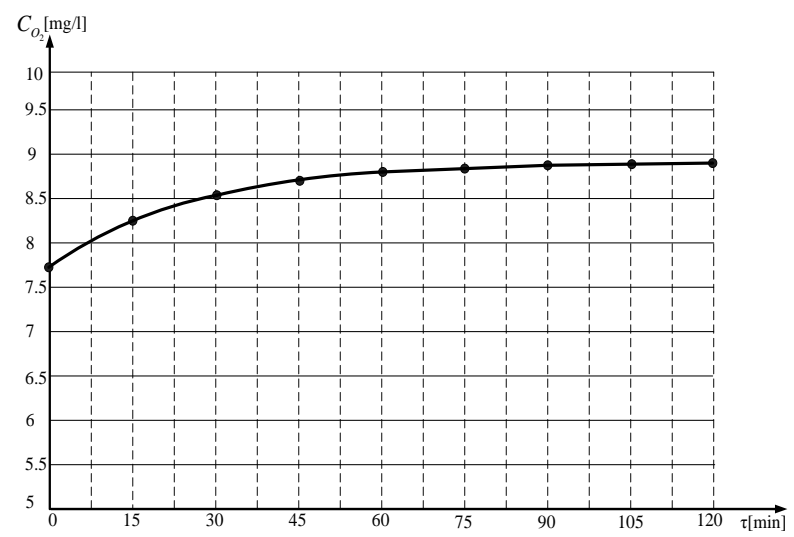

Figure 10. Graphical repreentation of the function $\mathrm{C}_{\mathrm{O} 2}=\mathrm{f}(\tau)$

\section{Conclusions}


1. The driving mechanism of the oxygen meter probe performs a $360^{\circ}$ rotation of the probe in 2 seconds; the movement is transmitted from the stepping motor, through a gear belt, to the probe carrier rod.

An accurate trajectory covered in a well determined time is thus guaranteed.

2. The electronic system of the driving mechanism can receive instructions through the knobs from the control panel; the knobs allow the accomplishment of a pre-established rotation sequence in both directions, with a speed of 0,5 rps.

3. The performed experimental researches proved the accuracy of probe displacement and the reliability of the driving mechanis $\mathrm{m}$.

4. The driving mechanism allows the horizontal and vertical displacement of the probe, observing pre-established conditions.

5. The researches will continue in order to extend this experimental model to an industrial scale.

\section{ACKNOWLEDGEMENTS}

The work has been funded by the Sectoral Operational Programme Human Resources Development 2007-2013 of the Romanian Ministry of Labour, Family and Social Protection through the Financial Agreement POSDRU/88/1.5/S/60203 and POSDRU/107/1.5/S/76903.

\section{REFERENCES}

[1] D. Robescu, a.o., Reliability of processes and plants for water treatment and purification (in Romanian), Technical Publishing House, Bucharest, 2002.

[2] G. Oprina, I. Pincovschi, Gh. Băran G, Hydro-gas-dynamics of aeration systems equipped with fine bubble generators (in Romanian), Politehnica Press, Bucharest, 2009.

[3] C. Wilson, Notes regarding water quality, Department of Soil and Water Science, Florida University, 2010.

[4] N. Băran, Gh. Băran, G. Mateescu, Research Regarding a New Type of Fine Bubble Generator, Romanian Review of Chemistry, vol. 61, no. 2, pp.196-199, ISSN 0034-7752, 2010.
[5] D. Robescu, D.L. Robescu, Methods, plants and equipment for the physical purification of wastewater (in Romanian), Bren Publishing House, Bucharest, 1999.

[6] G. Mateescu, Hydro-gas-dynamics of fine bubble generators (in Romanian), PhD Thesis, POLITEHNICA University of Bucharest, Faculty of Mechanical Engineering and Mechatronics, 2011.

[7] Instruction manual of the oxygen meter manufactured by HANNA Instruments, Canada, 2010.

[8] S. Kostrakievici, C. Rizescu, C. Udrea, - Elements of Mechatronics (in Romanian), Printech, Bucharest, 2000.

[9] N. Băran, Gh. Băran, "The hydrodynamics of bubbles generated by porous diffusers" (in Romanian), romanian Review of Chemistry, vol. 54, no. 5/2003, pp. 436-440.

[10] N. Băran, Al. S. Pătulea, I. M. Căluşaru, Computation of performance and efficienty of the water oxy genation process in non-stationary conditions, Efficacité énergétique - sources d'énergies renouvelables - protection de l'environnement COFRET'12, Sozopol, Bulgarie, 11 -13 June, pag 503-507, 2012.

[11] Al. Dobrovicescu, N. Băran, et al., Elements of Technical Thermodynamics, POLITEHNICA PRESS Publishing House, Bucharest, Romania, 2009.

[12] N. Băran, Gh. Băran, G. Mateescu, D. Besnea, “Experimental Research Regarding a New Type of Fine Bubble Generator”, Romanian Review Precision Mechanics Optics and Mechatronics, no.36/2009, pp.25-31, ISSN 1584-5982

[13] N. Băran, Gh. Băran, G. Mateescu, Al. Pătulea, Water oxigenation, Jassy Polytechnic University Sci. Bull, tome XI (LX) fasc. 3b., Ed. POLITEHNIUM, 77-84, 2010.

[14] G. Oprina, Contributions of the hydro-gas-dynamics of porous diffusers (in Romanian), PhD Thesis, POLITEHNICA University of Bucharest, 2007.

[15] N. Băran, A. Zaid, Al. Pătulea, Researches regarding the increase of the dissolved oxygen concentration in function of the duration of the water oxygenation process, TERMOTEHNICA, No .2/2010, pp. 15-18, ISSN 1222-4057.

[16] A. Călin, Theoretical and experimental contribution on the study of the reaeration preocess in biological reactors, $\mathrm{PhD}$ Thesis, Politehnica” University of Bucharest, 2010. 